\title{
METHANE GAS HYDRATE EFFECT ON SEDIMENT ACOUSTIC AND STRENGTH PROPERTIES
}

\author{
W.J. Winters ${ }^{1}$, W.F. Waite ${ }^{1}$, D.H. Mason ${ }^{1}$, L.Y. Gilbert ${ }^{1}$, and I.A. Pecher ${ }^{2}$ \\ ${ }^{1}$ U.S. Geological Survey, Woods Hole Science Center, 384 Woods Hole Road, Woods \\ Hole, MA 02543 USA \\ ${ }^{2}$ Institute of Geological \& Nuclear Science, 69 Gracefield Rd., Lower Hutt, New Zealand
}

Keywords: Acoustic modeling, acoustic velocity, cementation, gas hydrate, physical properties, shear strength

\begin{abstract}
To improve our understanding of the interaction of methane gas hydrate with host sediment, we studied: (1) the effects of gas hydrate and ice on acoustic velocity in different sediment types, (2) effect of different hydrate formation mechanisms on measured acoustic properties (3) dependence of shear strength on pore space contents, and (4) pore-pressure effects during undrained shear.

A wide range in acoustic p-wave velocities ( $\mathrm{Vp}$ ) were measured in coarse-grained sediment for different pore space occupants. Vp ranged from less than $1 \mathrm{~km} / \mathrm{s}$ for gascharged sediment to $1.77-1.94 \mathrm{~km} / \mathrm{s}$ for water-saturated sediment, $2.91-4.00 \mathrm{~km} / \mathrm{s}$ for sediment with varying degrees of hydrate saturation, and $3.88-4.33 \mathrm{~km} / \mathrm{s}$ for frozen sediment. Vp measured in fine-grained sediment containing gas hydrate was substantially lower $(1.97 \mathrm{~km} / \mathrm{s})$. Acoustic models based on measured Vp indicate that hydrate which formed in high gas flux environments can cement coarse-grained sediment, whereas hydrate formed from methane dissolved in the pore fluid may not.

The presence of gas hydrate and other solid pore-filling material, such as ice, increased the sediment shear strength. The magnitude of that increase is related to the amount of hydrate in the pore space and cementation characteristics between the hydrate and sediment grains. We have found, that for consolidation stresses associated with the upper several hundred meters of subbottom depth, pore pressures decreased during shear
\end{abstract}


in coarse-grained sediment containing gas hydrate, whereas pore pressure in fine-grained sediment typically increased during shear. The presence of free gas in pore spaces damped pore pressure response during shear and reduced the strengthening effect of gas hydrate in sands.

\section{Introduction}

Gas hydrate, a crystalline solid composed of natural gas and hydrogen-bonded water molecules, is formed at the relatively high pressure and low temperature conditions present along many continental margins and in the arctic (Kvenvolden and Lorenson 2001). Deposits of gas hydrate are a potential source of fuel because they concentrate methane, and to a lesser extent, other energy gases. However, to assess the resource potential of gas hydrate, hydrate-sediment interactions must be more fully explored.

Properties of the porous host sediment affect the morphology and extent of hydrate growth (Sloan 1998), which in turn alters the host sediment properties (Lee and Collett 2001). Seismic and other remote sensing techniques rely on those sediment alterations to map hydrate distributions (Kvenvolden and Lorenson 2001). When hydrate dissociates, however, the detrimental effect on strength can lead to slope or borehole instabilities, a process that must be understood to drill safely in regions containing significant amounts of hydrate.

The U.S. Geological Survey (USGS) is studying the formation, behavior, and properties of gas hydrate and sediment mixtures. Our goal is to understand the interaction between natural sediments and gas hydrate formation in order to quantify physical properties for use in predictive models that estimate quantity and behavior of gas hydrates in situ. We have performed acoustic velocity, triaxial shear strength, and other physical property measurements on samples containing natural hydrate recovered from drilled wells and on laboratory-formed gas hydrate. We have also performed tests on other samples with completely dry pores, completely water filled pores, and pores filled with ice. These measurements are being used to assess the importance of gas hydrate compared to other natural interstitial fillings. This paper discusses some of the key acoustic- and strength-related findings from our laboratory test program. 


\section{Laboratory Equipment}

The Gas Hydrate And Sediment Test Laboratory Instrument (GHASTLI) (Winters et al. 2000) simulates in situ pressure and temperature conditions in a cylindrical sediment sample that is typically $71 \mathrm{~mm}$ in diameter by $130-140 \mathrm{~mm}$ high (Fig. 1). A test specimen is jacketed between acoustically instrumented end caps using flexible membranes. A bath circulator is used to control the temperature of the sample chamber and of a heat exchanger located immediately above the top specimen end cap. Four thermocouples and four thermistors are placed against the outside perimeter of the specimen or end caps at different heights to measure temperature variations along the sample surface.

Four separately controllable 500-ml-capacity syringe pumps are used to maintain the confining pressure surrounding the specimen and internal specimen pressures. A back-pressure system contains a collector capable of separating and measuring water and gas volumes which are pushed out of the specimen by gas hydrate dissociation at test pressures (Winters et al. 2000). A separate, fifth, syringe pump controls the movement of the load ram during the shear phase of the test. The ram position is used to determine the specimen height. Load, pressure, temperature, and acoustic measurements from within the different subsystems and in close proximity to the test specimen are logged and displayed by a computer employing custom-designed Labview software.

\section{Experimental Methods}

During this study, three types of samples were tested in the laboratory: (a) medium-sized sandy sediment containing natural gas hydrate from the Mackenzie Delta, NWT, Canada; (b) reconstituted uniform medium-sized-sieved Ottawa sand (SOS); and (c) reconstituted Min-U-Sil-40 clayey silt.

Sediment specimens were transported from the Mackenzie Delta, NWT, Canada to Woods Hole, MA in stainless-steel vessels pressurized with methane gas (Winters et al. 1999b). The samples were kept frozen and were prepared for testing within a walk-in freezer maintained near $-30^{\circ} \mathrm{C}$. After the gas hydrate was stabilized within GHASTLI, the ice within the pore space was allowed to melt to return the sample to its in situ sub- 
permafrost conditions. Physical properties were measured throughout the test, including the ice melting stage.

Methane gas hydrate was formed in the laboratory within sieved Ottawa sand using two methods. Method 1 involved slowly pushing methane gas into an initially water-saturated sieved Ottawa sand sediment (e.g., GH069). Confining and pore pressures were simultaneously raised to $12 \mathrm{MPa}$, and then an additional consolidation stress, $\sigma_{c}^{\prime}$, was applied externally to the test specimen. Methane was slowly percolated up through the sediment until a pre-determined amount of water, measured by the collector, was pushed out of the sample. Then the temperature of the coolant flowing to the heat exchanger was lowered until P-T conditions were within the gas-hydrate-stability zone. To dissociate the gas hydrate the procedure was reversed; that is, the temperature was slowly raised until the phase boundary was crossed.

The second hydrate formation method, method 2, started with a specimen that was initially partly saturated with water. Because we did not want to change the initial water content, drainage during specimen pressurization was not allowed. Internal methane pressure and external confining pressure were incrementally raised to approximately 12 MPa. After pressurization was finished, an additional consolidation stress was applied. Method 2 was used to form hydrate in both sieved Ottawa sand (GH083, 084, 085) and Min-U-Sil-40 silt (GH090) samples.

Specimens used for index property calculations were dried at a temperature between 90 and $105^{\circ} \mathrm{C}$ for at least 24 hours in order to determine the amount of fresh water and solids present. The volume of dried solids was determined with an automatic gas pycnometer using helium as the purge and expansion gas (ASTM 1997). The grain density of the pycnometer specimen was calculated using the mass of solids as determined immediately prior to insertion of the sample into the pycnometer.

As appropriate, physical-property calculations were corrected for the presence of residual salt left on the solid particles after oven drying. In the natural environment, salt and other particles are dissolved in the pore fluid and behave as part of the aqueous phase. The calculations removed the salt precipitate from the solids and added it back to the fluid phase. Equations used to calculate grain density, porosity, and water content of the sediment are described in (Winters et al. 1999a). 
The grain size of coarse material (greater than $0.0625 \mathrm{~mm}$ diameter) was determined by dry sieving. The fine fraction (less than $0.062 \mathrm{~mm}$ diameter) was measured with a Galai 2010 and a Coulter counter particle size analyzer using time of transition theory (Syvitski 1991).

P-wave velocity was measured by pulse transmission through the cylindrical sample using $500 \mathrm{kHz}-1 \mathrm{MHz}$ (natural frequency) wafer-shaped crystals that are located

on the back side (away from the specimen) of each end cap. A 400-volt pulse was sent to the transmitting transducer, the received signal was amplified, digitized, displayed on a digital oscilloscope, and recorded by a computer. Acoustic p-wave velocity $\left(\mathrm{V}_{\mathrm{p}}\right)$ was calculated from the specimen length and measured acoustic travel time through the specimen.

During the shear strength phase of the test, specimen loading was produced by a ram contacting the heat exchanger which pushed on the sample. Samples were sheared at a constant rate (measured using a linear displacement transducer) that was slow enough to ensure equalization of pore pressure throughout the test specimen (Bishop and Henkle 1962). Load, confining pressure, pore pressures at the top and bottom end caps, and sample deformation (to a maximum of 15 - 20 percent axial strain) were measured and recorded.

\section{Results and Discussion}

\section{Sample Descriptions}

Although the natural samples from the Mackenzie Delta were obtained from different depths within the Mallik 2L-38 borehole, they possess remarkably similar textural characteristics (Table 1). Two thirds of each of the samples, by mass, were between the 1 to 2 phi sizes (coarse to medium sand). All of the sub-rounded, sieved Ottawa sand samples were medium sand. The Min-U-Sil-40 clayey silt was substantially finer-grained, containing less than one percent sand.

Water contents of analyzed samples (Mass of water/Mass of solids) ranged from 3.8 to 22.7 percent (Table 2). The initially partly water saturated SOS samples had the lowest values, followed by the Mallik samples (15.5 to 21.3 percent), and the clayey silt 
(22.7 percent) had the highest values. Water content measurements are important because they represent the quantity of water available to form gas hydrate.

Porosity values of all samples ranged from 28.6 to 49.0 percent (Table 2). The SOS samples varied from 32.7 to 39.4 percent, the Mallik samples varied from 28.6 to 40.75 percent, and the clayey silt had the highest porosity at 49 percent. Because porosity is a measure of the relative volume of the pore space in a sample and is independent of any particular pore-filling material, unlike water content, porosity measurements provide a means for comparing sample attributes. Previous studies have shown that for similar sediment types and test conditions, a higher porosity specimen would generate more positive pore pressure during shear, be weaker, and perhaps have lower acoustic velocity than a sample with lower porosity (Atkinson 1993; Carmichael 1982).

\section{Acoustic Velocity Measurements Effects of Pore Content}

Different pore filling materials in the void space of Mallik sand, SOS, and silt profoundly affected the compressional wave speed (Vp) (Tables 2 and 3). The properties measured from samples containing gas hydrate and water are typically most relevant to in situ conditions in the marine environment. However, p-wave velocity for samples containing ice are included to compare with gas-hydrate-bearing sediments postulated to occur within permafrost. Formation of gas hydrate in SOS sample GH069 increased Vp by $2.05 \mathrm{~km} / \mathrm{s}$ related to baseline, water-saturated sediment. However, simply freezing pore water (as in GH066) increased Vp by $2.37 \mathrm{~km} / \mathrm{s}$. Three factors contribute to this change in velocity: (a) the longitudinal wave speed of ice is slightly greater than that of structure I (methane) hydrate (Dvorkin et al. 2000; Kuustraa and Hammershaimb 1983), (b) the vast majority of the pore water is converted to ice during freezing in a coarsegrained sediment (Freitag and McFadden 1997), and (c) it is difficult to completely fill the void space of a coarse-grained sediment with gas hydrate using a method that simulates natural formation processes, meaning the hydrate-bearing samples contain a smaller percentage of solid material than their frozen counterparts. The presence of gas either greatly diminishes the velocity or attenuates initial high-frequency waveforms so that apparent velocity is decreased (Waite et al. 2004). 


\section{Effects of Sediment Grain Size}

Results from field observations show that grain size of host sediment may influence the type and quantity of hydrate formed. For example, in the Mackenzie Delta, NWT, Canada (Mallik 2L-38 well), hydrate typically is dispersed in coarser-grained units but not in adjacent silts (Dallimore et al. 1999; Winters et al. 1999a). Also, gas hydrates were found predominantly in sandier units in the Nankai Trough, off the coast of Japan (Uchida and Takashi 2004). However, in the Gulf of Mexico, where near-surface sediments were generally fine grained, hydrate in giant piston cores was present in massive layers and did not visually appear to be affected by lithologic changes (Lorenson et al. 2002; Winters et al. in press).

Test results from GH090, conducted on reconstituted clayey silt, indicate that pwave velocity increased during initial hydrate formation, and reached a maximum of 1.97 $\mathrm{km} / \mathrm{s}$ (Fig. 2). This velocity is much lower than Vp obtained from sieved Ottawa sand where Vp is $3.08 \mathrm{~km} / \mathrm{s}$ (Table 2, Sample GH085). The samples contained comparable amounts of gas hydrate (pore saturation greater than or equal to 21 percent and 19 percent, respectively). This difference is not totally unexpected, because normallyconsolidated, fine-grained sediment that has not been deeply buried, typically has lower acoustic velocity than coarser sediment (Christensen 1989). However, the result poses a challenge for interpreting field seismic data that lack sample-verified grain-size information.

\section{Effects of Free Gas}

Free gas is associated with hydrate at many offshore locations (Suess et al. 2001). In fact, without free gas most gas hydrate deposits would go undetected, because free gas is one way to create an impedance contrast that is necessary to form a Bottom Simulating Reflection (BSR) on seismic records (Paull et al. 2000a). BSR's are widely regarded as an important indicator of the presence of natural hydrate deposits (Dillon and Max 2000; Kvenvolden and Lorenson 2001).

The presence of free gas during hydrate formation greatly influences subsequent acoustic behavior. Our acoustic measurements and models indicate that cementation is likely in the presence of substantial amounts of free gas, because hydrate forms at locations coated with water molecules on grain surfaces and at grain contacts (Waite et 
al. 2004; Winters et al. 2004a). However, many natural samples are located in regions where free gas probably doesn't occur, because gas hydrate may form from dissolved gas (Buffett and Zatsepina 2000). Such occurrences do not appear to have grain cementation (Winters et al. 2004a). Because excess methane gas is typically used during laboratory experiments to form hydrate in sediment, understanding hydrate formation in dissolved gas environments requires a different experimental strategy, and supports the need for testing sediment samples containing gas hydrate formed from methane dissolved in the pore water.

\section{Strength Behavior and Pore Pressure Effects}

A knowledge of shear strength behavior and pore pressure response of sediments is crucial to predicting the potential for submarine slope instability and other geohazards (Holtz and Kovacs 1981; Lambe and Whitman 1969). Theoretically, strength is inversely related to excess pore pressure under identical loading conditions for similar materials. Gas hydrate dissociation has been implicated in a number of offshore slope instabilities (Buenz et al. 2003; Paull et al. 2000b). In addition, (Peltzer and Brewer 2000) stress the necessity of knowing in-situ pore pressure, because it affects the calculation of BSR depth. Although pore pressure is critical to gas-hydrate stability, little is known about it in either offshore gas hydrate or terrestrial permafrost regions. Pore pressures beneath permafrost may be similar to those beneath gas hydrate because both layers can act as a less permeable boundary to gas migration (Winters et al. 2002). Given the tendency of gas hydrate to reduce permeability in sediment, exploratory drilling or other mechanisms that open pathways between pressured zones separated by gas hydrate could potentially cause marked changes in local pore pressure, even without gas hydrate dissociation. Such effects could be similar to those produced by shallow-water flows (a rapid movement of sediment particles caused by equalization of pore pressure in different strata).

We performed triaxial strength tests on a number of reconstituted sieved Ottawa sand samples with different pore space materials to study the relative effect of gas hydrate and other pore fillings on sediment properties (Figure 3). Pore fillings consisted of: (1) substantial gas hydrate formed from initially water saturated sediment (GH069), (2) varying amounts of gas hydrate and methane formed from initially partly water 
saturated sediment (GH083, GH084, GH085), (3) water ice (GH066), (4) complete water saturation (GH079), and (5) air (GH080). This diverse data set was used to assess the importance of gas hydrate compared to other natural pore fillings and the influence of pore pressure on strength behavior.

The shear strength and pore pressure behavior (qmax and A coefficient, respectively, in Table 2) of coarse-grained sediment is related to a number of sample characteristics, including relative density, compressibility of the pore fillings, and cementation of sediment grains. In addition, test parameters including strain rate and consolidation stress also significantly affect behavior (Andersland and Ladanyi 1994). There are a number of reasons for the wide range in shear strengths exhibited by the samples tested in this study (Fig. 3). The relative density of samples influences moderate strain behavior because it determines how the sample changes volumetrically as it approaches the critical or very large strain state (Atkinson 1993). Very loose sediment tends to contract whereas very dense sediment tends to dilate in order to reach critical state. During undrained shear tests, which we performed as part of this study, the tendency to contract increased pore pressure, whereas dilatant material decreased pore pressure. However, the ability to generate and transmit pore pressure is dependent on the compressibility of the pore fluid. Pore pressure response was the greatest in a completely water saturated sample (GH079) (Fig. 4). The weakest sample contained completely dry void spaces (GH080), where the low strength resulted from an inability to develop negative pore pressure due to the low compressibility of the pore filling and a high initial porosity.

The presence of free gas influences behavior of samples containing gas hydrate (GH069 and GH083). Because of the presence of hydrate, the shear strength is greater than that of the water-saturated SOS sample, even though the pore pressure response of GH069 is not as great as GH079 (Fig. 4). When free gas is not present, the dilatational tendency of hydrate-containing sandy sediment causes a tremendous decrease in pore pressure (and an increase in strength) compared to water-saturated sediment (Winters et al. 1999b). Without the residual free gas present in samples GH069 and GH083, pore pressure would have decreased more and the shear strength could very well have been substantially greater than that of the frozen specimen (GH066). Undrained strength is 
related to the amount of hydrate, ice, water, and methane present in the sample's pores at the time of shear. Although our hydrate formation techniques (methods 1 and 2) model in situ conditions in a high-gas-flux environment very well, additional experiments are needed to model geologic conditions without free gas.

For the consolidation stresses examined in this study, the overall pore pressure response during shear is determined primarily by the sediment grain size. All the sandy samples exhibit a negative pore pressure response (negative A coefficient value, Table 2; Fig. 4), while the fine-grained clayey silt sample had a positive pore pressure response (positive A coefficient value, Table 2; Fig. 4).

Another important finding from the test series is the close agreement in behavior between tests GH069 (initially water saturated) and GH083 (initially containing water and gas) (Fig. 3). Both samples had substantial amounts of gas hydrate in the pore space during shear. In addition to the similarity in final p-wave velocity (3.95 versus $4.00 \mathrm{~km} / \mathrm{s}$, respectively) of these specimens, the stress-strain behavior is nearly identical as well (Fig. 3). Although specimens that are initially water saturated (gas hydrate formation method 1) more closely replicate natural conditions, method 2 produces more consistent laboratory results. The results from these two tests show that both methods can produce nearly identical results when simulating hydrate formation in high gas flux environments.

\section{Conclusions}

The precise control of test conditions using GHASTLI provides a means for studying acoustic and shear strength behavior of sediment samples that contain gashydrate and other pore filling materials. During this study, three types of samples were tested in the laboratory: (a) medium-sized sandy sediment containing natural gas hydrate; (b) reconstituted uniform medium-sized sieved Ottawa sand (SOS); and (c) reconstituted Min-U-Sil-40 clayey silt.

A wide range in acoustic p-wave velocities were measured. The dependence on pore content was dramatic varying from less than $1 \mathrm{~km} / \mathrm{s}$ for gas-charged sediment to $4.00 \mathrm{~km} / \mathrm{s}$ or more for sediment containing different pore saturations of hydrate and ice. Vp also showed a dependence on grain size and was substantially lower in fine-grained

sediment containing gas hydrate than in coarse-grained sediment with a comparable 
amount of pore-space hydrate. Acoustic wave speeds also depend on the hydrate formation technique. We find that hydrate forming in high gas flux environments cements coarse-grained sediment significantly increasing Vp, whereas hydrate formed from methane dissolved in the pore fluid may not cement grains and may consequently have a smaller impact on $\mathrm{Vp}$.

The presence of gas hydrate and other solid pore-filling material, such as ice, increased the shear strength of sediment. The magnitude of that increase was related to the amount of hydrate in the pore space, which accentuates the pore pressure response, and free gas which dampens the response. Pore pressures decreased during shear in coarse-grained sediment containing gas hydrate, whereas pore pressure in fine-grained sediment typically increased during shear.

\section{Acknowledgments}

The authors thank D. Twichell and R. Oldale for their helpful comments. This work was supported by the Coastal and Marine Geology, and Energy Programs of the U.S. Geological Survey and funding was provided by the Gas Hydrate Program of the U.S. Department of Energy. 


\section{Captions}

Table 1. Results of texture analyses

Table 2. Specimen properties and test parameters

Table 3. Compressional wave velocities, $\mathrm{Vp},(\mathrm{km} / \mathrm{s})$ of different materials measured in GHASTLI

Figure 1. Close-up view of a test specimen about to be raised into the main pressure vessel (visible at the top of the photograph). The test specimen (gray cylinder) is located in the central part of the photo and rests on an interchangeable internal load cell. A heat exchanger that imparts a unidirectional cooling front downward through the specimen rests atop the upper end cap, fed through the large diameter, vertical tubes at the front and rear of the specimen (Winters et al. 2000).

Figure 2. P-wave velocity versus elapsed time within the methane gas hydrate stability field for a clayey silt (GH090) and sieved Ottawa sand (GH083, 84, 85) samples tested using GHASTLI.

Figure 3. Shear-stress versus axial-strain plots for sieved Ottawa sand specimens containing various materials in the pore space (Winters et al. 2004b).

Figure 4. Pore pressure change versus strain results for sieved Ottawa sand (SOS) (GH066, GH069, GH079, GH080, GH083, GH084), and clayey silt (GH090). The coarse-grained sediment containing gas hydrate and other pore fillings exhibited dilatant behavior as illustrated by the generation of negative (related to the beginning of shear) pore pressure. Contrast this behavior with the positive pore pressure response of GH090. GH083 contained a significant amount of gas hydrate that filled the sediment pores resulting in little pore pressure response. 


\section{REFERENCES}

Andersland, O. B., and Ladanyi, B. (1994). An introduction to frozen ground engineering, Chapman \& Hall, New York.

ASTM. (1997). "Standard test method for specific gravity of solids by gas pycnometer D5550-94." Annual Book of ASTM Standards, v. 04.09, Soil and Rock, American Society for Testing and Materials, West Conshohocken, Pennsylvania, 380-383.

Atkinson, J. (1993). An Introduction to the Mechanics of Soils and Foundations Through Critical State Soil Mechanics, McGraw-Hill Book Company, London.

Bishop, A. W., and Henkle, D. J. (1962). The Measurement of Soil Properties in the Triaxial Test, Edward Arnold (Publishers) LTD, London.

Buenz, S., Mienert, J., and Berndt, C. (2003). "Geological controls on the Storegga gashydrate system of the mid-Norwegian continental margin." Earth and Planetary Science Letters, 209(3-4), 291-307.

Buffett, B. A., and Zatsepina, O. Y. (2000). "Formation of gas hydrate from dissolved gas in natural porous media." Marine Geology, 164(1-2), 69-77.

Carmichael, R. S. (1982). Handbook of Physical Properties of Rocks, CRC Press, Inc., Boca Raton, FL.

Christensen, N. I. (1989). "Seismic velocities." Practical Handbook of Physical Properties of Rocks and Minerals, R. S. Carmichael, ed., CRC Press, Boca Raton, FL, 429546.

Dallimore, S. R., Collett, T. S., and Uchida, T. (1999). "Overview of science program, JAPEX/JNOC/GSC Mallik 2L-38 gas hydrate research well." Bulletin Geological Survey of Canada, Report: 544, 11-17.

Dillon, W. P., and Max, M. D. (2000). "The U.S. Atlantic continental margin; the bestknown gas hydrate locality." Natural Gas Hydrate in Oceanic and Permafrost Environments, M. D. Max, ed., Kluwer Academic Publishers, Dordrecht, The Netherlands, 157-170.

Dvorkin, J., Helgerud, M. B., Waite, W. F., Kirby, S. H., and Nur, A. (2000).

"Introduction to physical properties and elasticity models." Natural Gas Hydrate in Oceanic and Permafrost Environments, M. D. Max, ed., 245-260.

Freitag, D. R., and McFadden, T. (1997). Introduction to cold regions engineering, ASCE Press, New York.

Holtz, R. D., and Kovacs, W. D. (1981). An Introduction to Geotechnical Engineering, Prentice-Hall, Inc., Englewood Cliffs, NJ.

Kuustraa, V. A., and Hammershaimb, E. C. (1983). "Handbook of Gas Hydrate Properties and Occurrence." DOE/ MC /19239-1546, Lewin and Associates.

Kvenvolden, K. A., and Lorenson, T. D. (2001). "The global occurrence of natural gas hydrate." Natural Gas Hydrates Occurrence, Distribution, and Detection Geophysical Monograph 124, C. K. Paull and W. P. Dillon, eds., Am. Geophysical Union, Washington, D.C., 3-18.

Lambe, T. W., and Whitman, R. V. (1969). Soil Mechanics, John Wiley \& Sons, New York.

Lee, M. W., and Collett, T. S. (2001). "Elastic properties of gas hydrate-bearing sediments." Geophysics, 66(3), 763-771. 
Lorenson, T. D., Winters, W. J., Hart, P. E., and Paull, C. K. (2002). "Gas hydrate occurrence in the northern Gulf of Mexico studied with giant piston cores." Eos, Transactions, American Geophysical Union, 83(51), 601.

Paull, C. K., Matsumoto, R., Wallace, P. J., Black, N. R., Borowski, W. S., Collett, T. S., Damuth, J. E., Dickens, G. R., Egeberg, P. K., Goodman, K., Hesse, R. F., Hiroki, Y., Holbrook, W. S., Hoskins, H., Ladd, J., Lodolo, E., Lorenson, T. D., Musgrave, R. J., Naehr, T. H., Okada, H., Pierre, C., Ruppel, C. D., Satoh, M., Thiery, R., Watanabe, Y., Wehner, H., Winters, W. J., and Wood, W. T. (2000a). "Leg 164 overview." Proceedings of the Ocean Drilling Program, Scientific Results, 164, 3-10.

Paull, C. K., Ussler, W., III, and Dillon, W. P. (2000b). "Potential role of gas hydrate decomposition in generating submarine slope failures." Natural Gas Hydrate in Oceanic and Permafrost Environments, M. D. Max, ed., Kluwer Academic Publishers, Dordrecht, The Netherlands, 149-156.

Peltzer, E. T., and Brewer, P. G. (2000). "Practical physical chemistry and empirical predictions of methane hydrate stability." Coastal Systems and Continental Margins - Natural Gas Hydrate in Oceanic and Permafrost Environments, M. D. Max, ed., Kluwer Academic Publishers, Dordrecht, The Netherlands, 17-28.

Sloan, E. D., Jr. (1998). Clathrate Hydrates of Natural Gases, Marcel Dekker, Inc., New York.

Suess, E., Torres, M. E., Bohrmann, G., Collier, R. W., Rickert, D., Goldfinger, C., Linke, P., Heuser, A., Sahling, H., Heeschen, K., Jung, C., Nakamura, K., Greinert, J., Pfannkuche, O., Trehu, A., Klinkhammer, G., Whiticar, M. J., Eisenhauer, A., Teichert, B., and Elvert, M. (2001). "Sea floor methane hydrates at Hydrate Ridge, Cascadia Margin." Natural Gas Hydrates: Occurrence, Distribution, and Detection, Geophysical Monograph 124, C. K. Paull and W. P. Dillon, eds., American Geophysical Union, Washington, DC, 87-98.

Syvitski, J. P. M. (1991). Principles, Methods, and Application of Particle Size Analysis, Cambridge University Press, Cambridge.

Uchida, T., and Takashi, T. (2004). "Petrophysical properties of natural gas hydratesbearing sands and their sedimentology in the Nankai Trough." Resource Geology, 54(1), 79-87.

Waite, W. F., Winters, W. J., and Mason, D. H. (2004). "Methane hydrate formation in partially water-saturated Ottawa sand." American Mineralogist, 89(8-9), 12021207.

Winters, W. J., Dallimore, S. R., Collett, T. S., Katsube, T. J., Jenner, K. A., Cranston, R. E., Wright, J. F., Nixon, F. M., and Uchida, T. (1999a). "Physical properties of sediments from the JAPEX/JNOC/GSC Mallik 2L-38 gas hydrate research well." Bulletin - Geological Survey of Canada, Report: 544, 95-100.

Winters, W. J., Dillon, W. P., Pecher, I. A., and Mason, D. H. (2000). "GHASTLI determining physical properties of sediment containing natural and laboratoryformed gas hydrate." Coastal Systems and Continental Margins - Natural gas Hydrate in Oceanic and Permafrost Environments, M. D. Max, ed., Kluwer Academic Publishers, Dordrecht, Netherlands, 311-322.

Winters, W. J., Lorenson, T. D., Paull, C. K., and Balut, Y. (in press). "Coring and Gas Hydrate Related Operations During the IMAGES VIII/PAGE 127 Gas Hydrate 
and Paleoclimate Cruise on the RV Marion Dufresne in the Gulf of Mexico, 2-18 July 2002." Initial report of the IMAGES VIII/PAGE 127 gas hydrate and paleoclimate cruise on the RV Marion Dufresne in the Gulf of Mexico, 2-18 July 2002, W. J. Winters, T. D. Lorenson, and C. K. Paull, eds., U.S. Geological Survey, Reston, VA.

Winters, W. J., Pecher, I. A., Booth, J. S., Mason, D. H., Relle, M. K., and Dillon, W. P. (1999b). "Properties of samples containing natural gas hydrate from the JAPEX/JNOC/GSC Mallik 2L-38 gas hydrate research well, determined using Gas Hydrate And Sediment Test Laboratory Instrument (GHASTLI)." Bulletin Geological Survey of Canada, Report: 544, 241-250.

Winters, W. J., Pecher, I. A., Waite, W. F., and Mason, D. H. (2004a). "Physical properties and rock physics models of sediment containing natural and laboratoryformed methane gas hydrate." American Mineralogist, 89(8-9), 1221-1227.

Winters, W. J., Waite, W. F., and Mason, D. H. (2004b). "Strength and acoustic properties of Ottawa sand containing laboratory-formed methane gas hydrate." Recent Advances in the Study of Gas Hydrates, C. E. Taylor and J. T. Kwan, eds., Kluwer Academic/Plenum Publishers, New York, NY, 213-226.

Winters, W. J., Waite, W. F., Mason, D. H., Dillon, W. P., and Pecher, I. A. (2002). "Sediment properties associated with gas hydrate formation." 4th International Conference on Gas Hydrates, 722-727. 
Table 1. Results of texture analyses

\begin{tabular}{|c|c|c|c|c|c|c|c|c|c|}
\hline & & (phi) & $(\mathrm{mm})$ & $\begin{array}{c}\text { Mallik } \\
\text { GH058 } \\
\left(\% 0^{-}\right. \\
\text {retained) }\end{array}$ & $\begin{array}{c}\text { Mallik } \\
\text { GH059 } \\
\left(\%{ }^{-}\right. \\
\text {retained) }\end{array}$ & $\begin{array}{c}\text { Mallik } \\
\text { GH060 } \\
(\%- \\
\text { retained) }\end{array}$ & $\begin{array}{c}\text { Mallik } \\
\text { GH062 } \\
(\%- \\
\text { retained) }\end{array}$ & $\begin{array}{c}\text { Sieved } \\
\text { Ottawa } \\
\text { Sand } \\
(\%- \\
\text { retained) }\end{array}$ & $\begin{array}{c}\text { Min-U- } \\
\text { Sil-40 } \\
\text { Silt } \\
\text { GH090 } \\
\text { (\%- } \\
\text { retained) }\end{array}$ \\
\hline $\begin{array}{r}\text { Gravel } \\
\text { Total }\end{array}$ & $\begin{array}{l}\text { med } \\
\text { fine } \\
\mathrm{v} \text { fine }\end{array}$ & $\begin{array}{l}-3 \\
-2 \\
-1\end{array}$ & $\begin{array}{l}8.0 \\
4.0 \\
2.0\end{array}$ & $\begin{array}{l}2.61 \\
0.00 \\
0.57 \\
3.18\end{array}$ & $\begin{array}{l}3.38 \\
0.00 \\
0.19 \\
3.57\end{array}$ & $\begin{array}{l}0.00 \\
0.00 \\
\underline{0.00} \\
0.00\end{array}$ & $\begin{array}{l}0.00 \\
0.00 \\
0.00 \\
0.00\end{array}$ & & \\
\hline Sand & $\begin{array}{c}\mathrm{v} \text {-coarse } \\
\text { coarse } \\
\text { med } \\
\text { fine } \\
\mathrm{v} \text { fine }\end{array}$ & $\begin{array}{l}0 \\
1 \\
2 \\
3 \\
4\end{array}$ & $\begin{array}{c}1.0 \\
0.5 \\
0.25 \\
0.125 \\
0.0625\end{array}$ & $\begin{array}{r}0.60 \\
7.46 \\
67.69 \\
14.25 \\
\underline{3.07} \\
93.07\end{array}$ & $\begin{array}{r}0.09 \\
6.62 \\
65.93 \\
16.21 \\
\underline{3.83} \\
92.67\end{array}$ & $\begin{array}{r}0.00 \\
2.58 \\
68.66 \\
15.49 \\
\underline{5.16} \\
91.90\end{array}$ & $\begin{array}{r}0.02 \\
2.07 \\
69.99 \\
16.66 \\
\underline{4.18} \\
92.93\end{array}$ & $\overline{100.00}$ & $\frac{0.06}{0.06}$ \\
\hline Silt & & 8 & 0.0039 & 2.53 & 2.49 & 6.93 & 5.64 & 0.00 & 66.50 \\
\hline Clay & & & & 1.22 & 1.27 & 1.17 & 1.43 & 0.00 & 33.44 \\
\hline
\end{tabular}


Table 2. Specimen properties and test parameters.

\begin{tabular}{|c|c|c|c|c|c|c|c|c|c|c|c|c|c|c|}
\hline Test ID (GH) & 58 & 59 & 60 & 62 & 66 & 67 & 69 & 73 & 79 & 80 & 83 & 84 & 85 & 90 \\
\hline \multicolumn{15}{|l|}{ General Information } \\
\hline Contains GH? & Yes & Yes & Yes & Yes & N/A & N/A & Yes & N/A & N/A & $\mathrm{N} / \mathrm{A}$ & Yes & Yes & Yes & Yes \\
\hline Material type/location & MD & $\mathrm{MD}$ & MD & $\mathrm{MD}$ & SOS & MD -(GHO62) & SOS & MD-(GH062, 67, 71) & sos & sos & sos & sos & sos & Silt \\
\hline Test procedure & 1 & 1 & 1 & 1 & 5 & 5 & 4 & 8 & 8 & 9 & 11 (70\%wat) & 11 (40\%wat) & 11 (20\%wat) & 11 (60\%wat) \\
\hline Top depth $(\mathrm{m})$ & 913 & 913.13 & 898.97 & 899.23 & & & & & & & & & & \\
\hline Bottom depth $(m)$ & 913.13 & 913.26 & 899.1 & 899.36 & & & & & & & & & & \\
\hline Pore water & Natural & Natural & Natural & Natural & DW ice (q) & DW ice & DW & DW & DW & None & DW & DW & DW & DW \\
\hline GH formation technique & Natural GH & Natural GH & Natural GH & Natural GH & $\mathrm{N} / \mathrm{A}$ & $\mathrm{N} / \mathrm{A}$ & \begin{tabular}{|l|} 
Init fully sat \\
\end{tabular} & N/A & $\mathrm{N} / \mathrm{A}$ & N/A & \begin{tabular}{|l|} 
Init partly sat \\
\end{tabular} & \begin{tabular}{|l|} 
Init partly sat \\
\end{tabular} & Init partly sat & Init partly sat \\
\hline \multicolumn{15}{|l|}{ Init Index Physical Properties } \\
\hline Water content (Mw/Ms) (\%) & 21.3 & 20.6 & 15.5 & 17.9 & 18.5 & 15.1 & 18.5 & 16.4 & 18.98 & 0 & 12.9 & 7.8 & 3.8 & 22.7 \\
\hline Pore water salinity (ppt) & 12 & 12 & 4 & 4 & 0 & 4 & 30 & 0 & 0 & 0 & 0 & 0 & 0 & 0 \\
\hline Grain densitv $\left(a / \mathrm{cm}^{3}\right)$ & 2.65 & 2.65 & 2.65 & 2.65 & 2.65 & 2.65 & 2.65 & 2.65 & 2.65 & 2.65 & 2.65 & 2.65 & 2.65 & 2.65 \\
\hline Porosity - ave (mass \& meas) (\%) & 38.55 & 40.75 & 34 & 37.45 & 32.65 & 28.6 & 32.8 & 31.6 & 33.0495 & 39.445 & 36.9 & 39.4 & 37.9 & 49 \\
\hline & & & & & & & & & & & & & & \\
\hline \multicolumn{15}{|l|}{ Gas and GH Quantity } \\
\hline Voids filled with GH at $90 \%$ occ (\%) & - & - & 50.3 & 69.2 & - & - & $<100(x)$ & - & - & - & 70 & 37 & 19.4 & 21.4 \\
\hline & & & & & & & & & & & & & & \\
\hline \multicolumn{15}{|l|}{ Velocities } \\
\hline$V p$ baseline $(\mathrm{km} / \mathrm{s})$ & $1.80(\mathrm{f})$ & $1.54(\mathrm{~h}, \mathrm{k})$ & $1.77(\mathrm{~h})$ & - & 1.86 & 1.86 & 1.9 & 1.89 (ai) & 1.861 (ai) & & 0.86 & 1.4 & - & 0.67 \\
\hline $\mathrm{Vp}(\mathrm{km} / \mathrm{s})$ & $2.73(\mathrm{~d})$ & & $2.37(\mathrm{~g})$ & $2.65(\mathrm{j})$ & $1.91(\mathrm{~h})$ & & & $1.9(\mathrm{aj})$ & $1.915(\mathrm{aj})$ & & & & & \\
\hline$V p(\mathrm{~km} / \mathrm{s})$ & & & & $2.61(\mathrm{~g})$ & & & & & & & & & & \\
\hline Vp max $(\mathrm{km} / \mathrm{s})$ & $3.23(\mathrm{e})$ & $2.91(\mathrm{~g})$ & 3.88 (d) & $2.8(d)$ & $4.23(p)$ & $4.33(p)$ & 3.95 & $1.94(\mathrm{bn})$ & & & 4.00 & 3.36 & 3.08 & 1.97 \\
\hline & & & & & & & & & & & & & & \\
\hline \multicolumn{15}{|l|}{ Strength Properties } \\
\hline Pore contents during shear & water & water & water & GH/water & Ice & & GH/water & & Water & Air & GH/DW/Gas & GH/DW/Gas & GH/DW/Gas & GH/DW/Gas \\
\hline Consolidation stress, o'c (MPa) & 0.24 & 0.22 & 0.26 & 0.36 & - & & 0.34 & & 0.252 & 0.248 & 0.235 & - & 0.266 & 4.89 \\
\hline "A" coefficient at failure & -0.33 & -0.31 & -0.26 & -0.26 & - & & -0.131 & & -0.4 & 0 & -0.0005 & -0.18 & -0.192 & 0.12 \\
\hline $\mathrm{q}$ at failure (qmax) $(\mathrm{MPa})$ & 1.55 & 1.38 & 0.82 & 6.69 & 11.17 & & 10.42 & & 7.734 & 0.39 & 10.111 & 2.613 & 2.445 & 4.739 \\
\hline Axial strain at failure (\%) & 15 & 13.4 & 15 & 8.8 & 11.46 & & 4.22 & & 10.25 & 6.96 & 4.657 & 15.02 & 11.41 & 16.81 \\
\hline \multicolumn{15}{|l|}{ Abbreviations: } \\
\hline \multicolumn{15}{|c|}{$\begin{array}{l}\text { Abbreviations: } \\
\text { DW - Distilled water; EC - End cap; FW - Fresh Water; GH - Gas hydrate; MD - Mackenzie Delta; Ms - Mass of solids; Mw - Mass of water; N/A -Not applicable; Nat - natural; SOS- sieved OS (1-2 phi); SW - Seawater }\end{array}$} \\
\hline \multicolumn{15}{|c|}{\begin{tabular}{|l|l|l|l|l|l|l|l|l|l|} 
Test Procedure: & & & & & & & & & \\
\end{tabular}} \\
\hline \multicolumn{15}{|c|}{1 - Natural GH in sediment; 4 - Init sat, push in methane, temp down; 5 - Freeze DW in pores; 8 - Wet pluviation, no methane introduced; 9 - Dry SOS; 11 - Initially partially water saturated } \\
\hline \multirow{2}{*}{\multicolumn{15}{|c|}{ 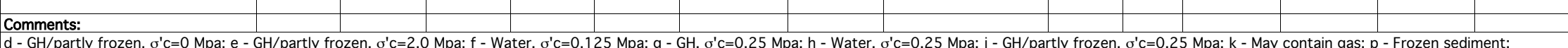 }} \\
\hline & & & & & & & & & & & & & & \\
\hline \multicolumn{15}{|c|}{$q$ - Internal temps $=-3.8$ to $-1.9^{\circ} \mathrm{C} ; \mathrm{x}$ - Visually observed full GH cementation; ai $-\sigma^{\prime} \mathrm{c}=0 \mathrm{Mpa} ; \mathrm{aj}-\sigma^{\prime} \mathrm{c}=0.25 \mathrm{Mpa} ; \mathrm{bn}-\sigma^{\prime} \mathrm{c}=1.0 \mathrm{Mpa}$} \\
\hline \multirow{2}{*}{\multicolumn{15}{|c|}{\begin{tabular}{|l|l|l|l|l|l|l|l|l|l|l|} 
Notes: & & & & & & \\
\end{tabular}}} \\
\hline & & & & & & & & & & & & & & \\
\hline \multirow{2}{*}{\multicolumn{15}{|c|}{$\begin{array}{l}\text { GH058, GH059, GH060 were sheared after gas hydrate dissociation, refreezing, re-jacketing, and re-consolidation procedures } \\
\text { GH062 was stopped at } 8.8 \% \text { axial strain to prevent membrane rupture due to high negative pore pressures }\end{array}$}} \\
\hline & & & & & & & & & & & & & & \\
\hline \multirow{2}{*}{\multicolumn{15}{|c|}{ "A" coefficient at failure = change in pore pressure/change in deviator stress }} \\
\hline$q=$ shear stress acting on a plane inc & lined at $45^{\circ}$ & from the hor & & & & & & & & & & & & \\
\hline
\end{tabular}


Table 3. Compressional Wave Velocities, $\mathrm{Vp},(\mathrm{km} / \mathrm{s})$ of Different Materials Measured in GHASTLI

\begin{tabular}{|l|l|}
\hline Fresh water: 1.5 & Ice: 3.83 \\
\hline Natural MD (water saturated) (max): $1.77-1.80$ & SOS (water saturated): $1.86-1.90$ \\
\hline MD (reconstituted, water sat): $1.86-1.94$ & SOS (w/GH) (max): 4.00 \\
\hline MD (w/ natural GH) (max): 2.91 & SOS (frozen): 4.23 \\
\hline MD (w/ natural GH \& ice)(max):3.88 & Min-U-Sil-40 silt (gas charged): 0.67 \\
\hline MD (reconstituted, frozen): 4.33 & Min-U-Sil-40 silt (peak): 1.97 \\
\hline
\end{tabular}

Note: $\mathrm{MD}=$ Mallik 2L-38 sediment;

$\mathrm{SOS}=$ reconstituted, sieved Ottawa sand;

$\mathrm{GH}=$ gas hydrate 


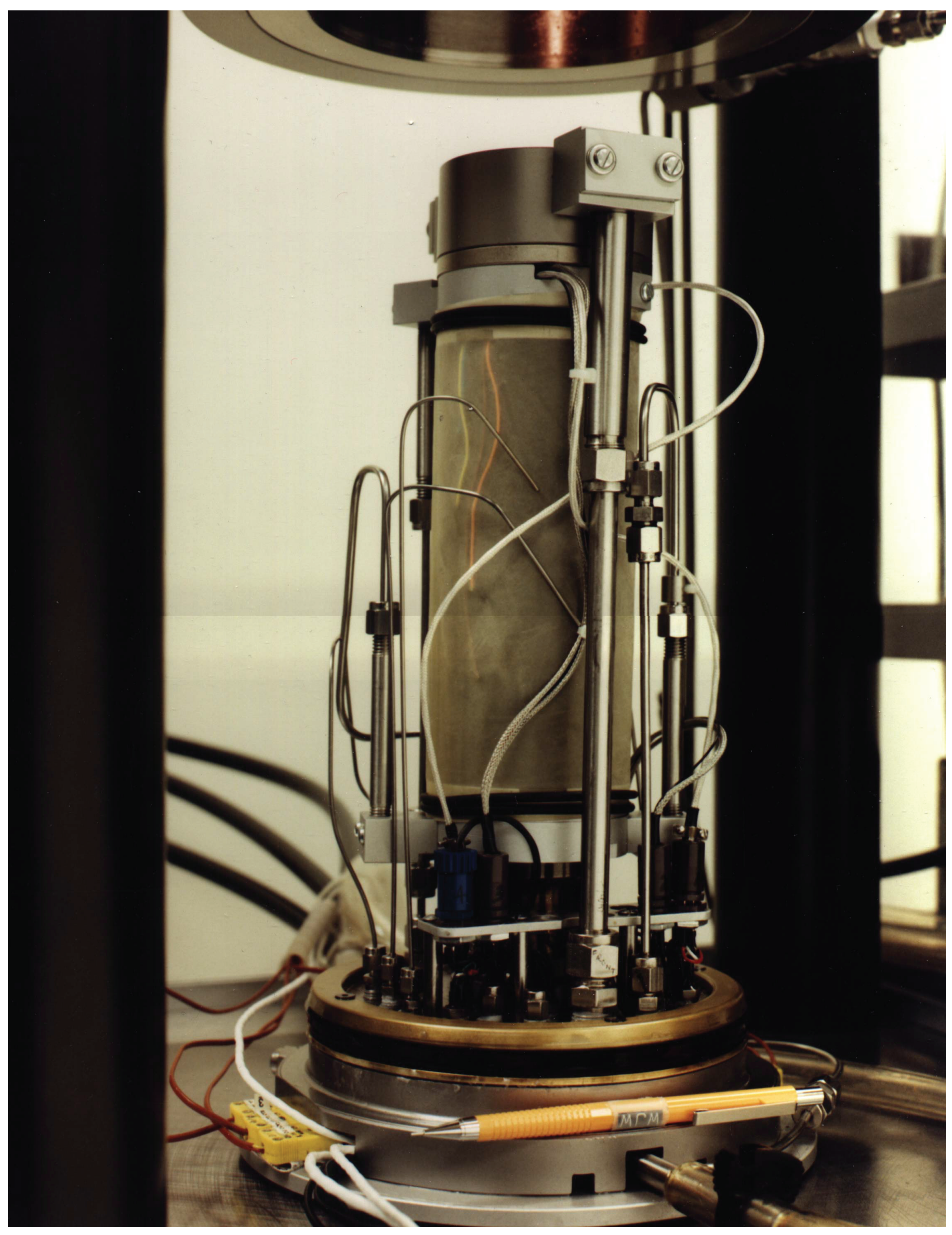




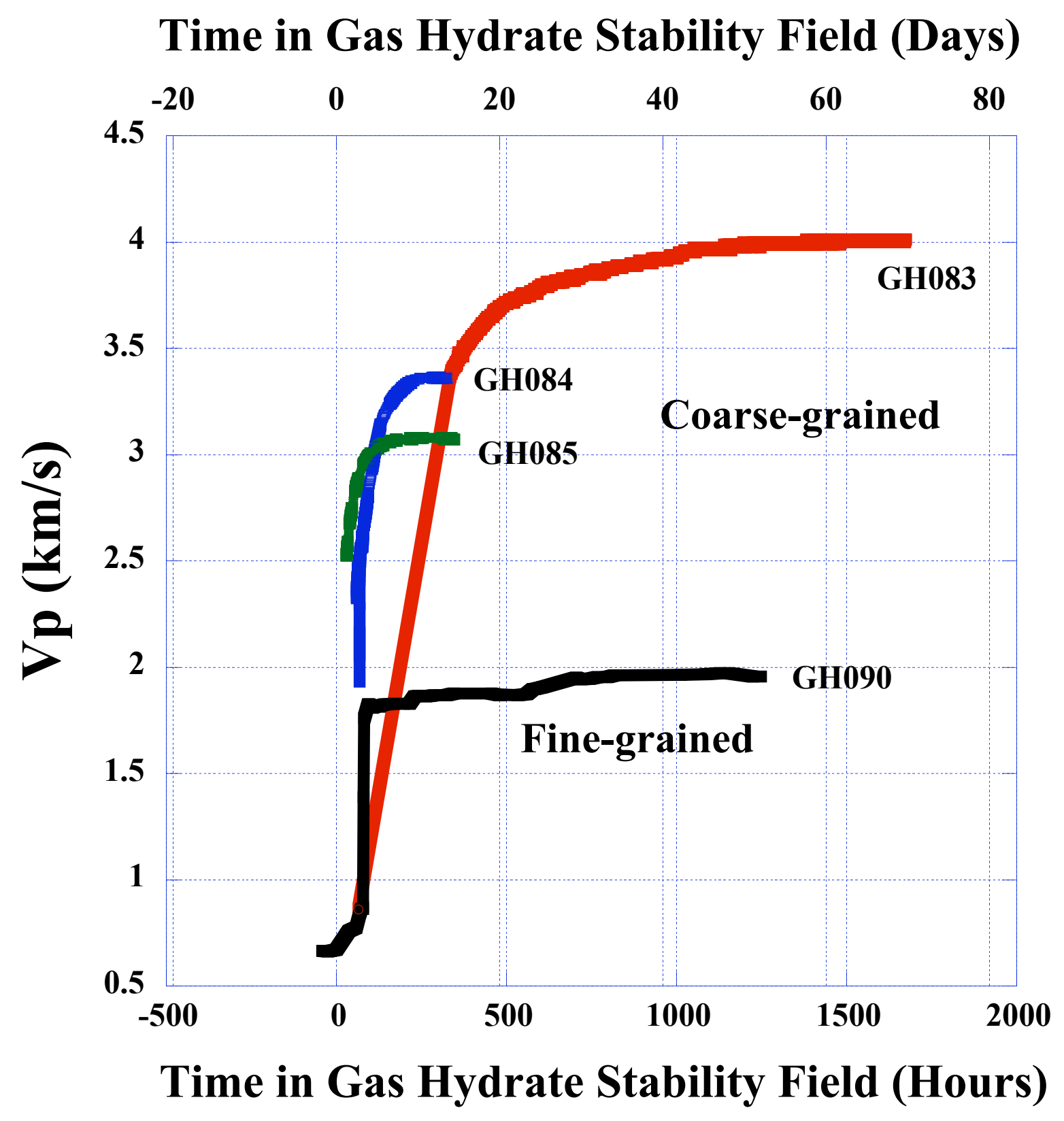




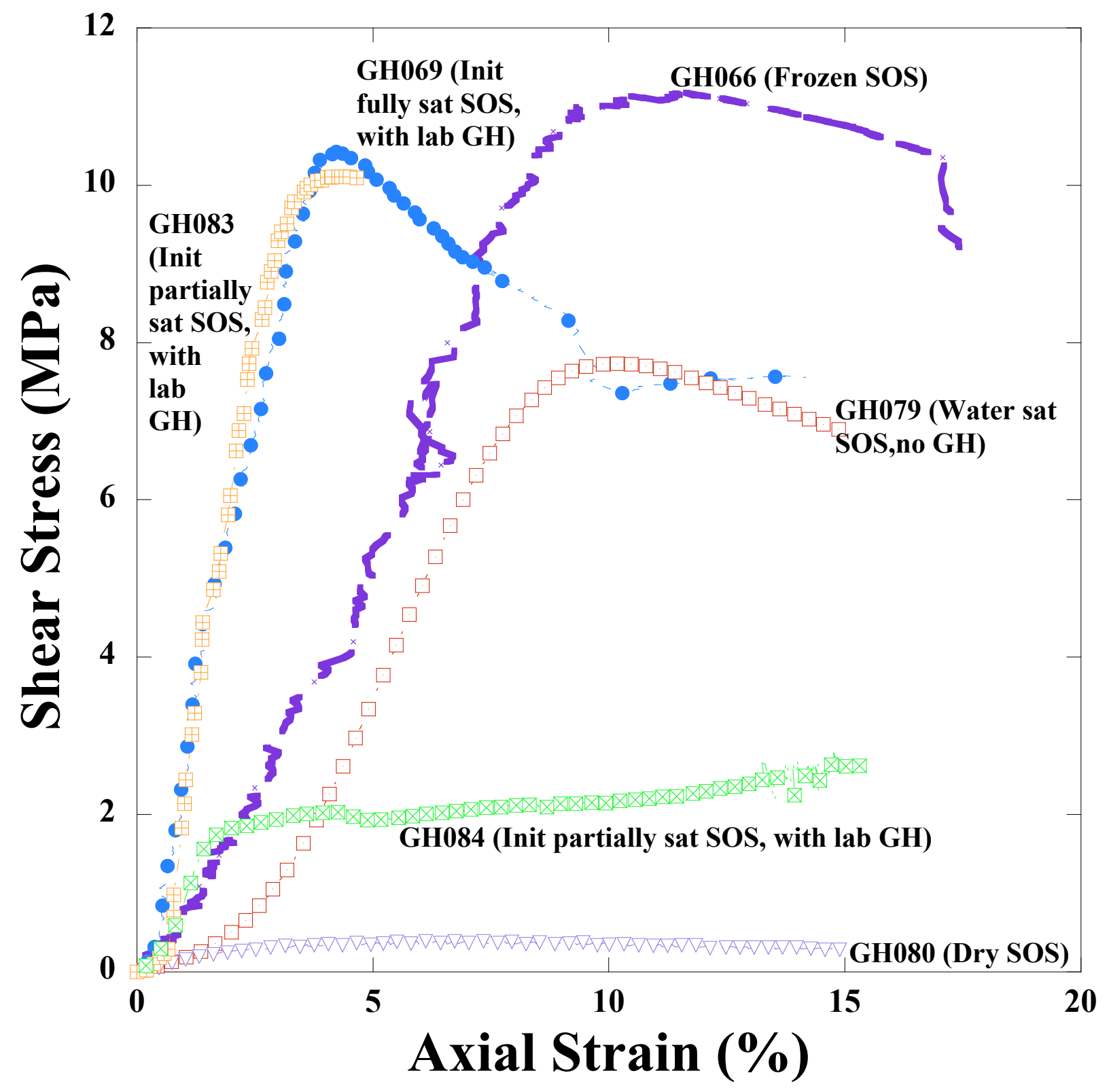




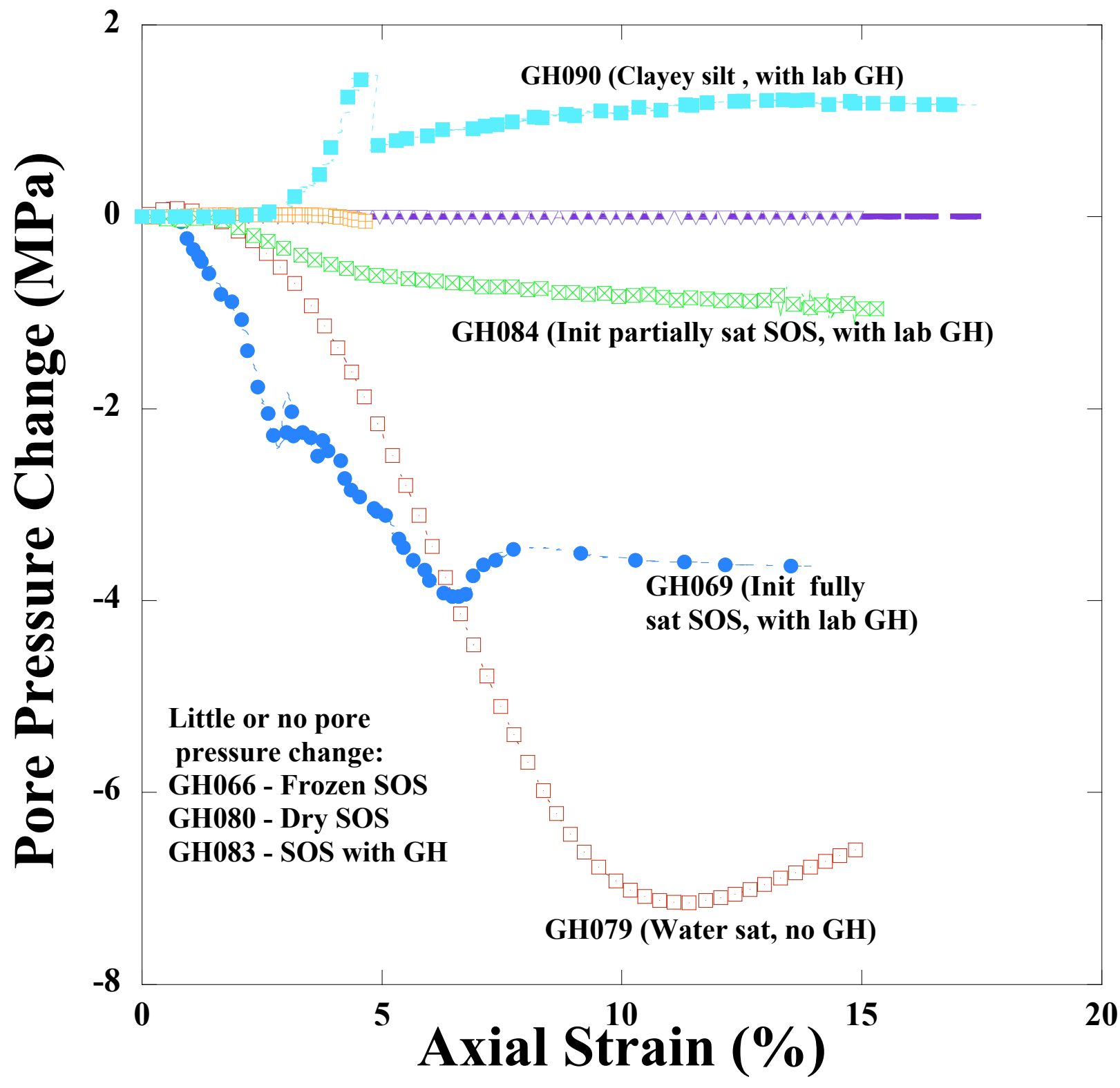

